\title{
PRODUÇÃO SEMISSÓLIDA DE METARHIZIUM ANISOPLIAE E BEAUVERIA BASSIANA EM DIFERENTES SUBSTRATOS E EFEITO DA RADIAÇÃO ULTRAVIOLETA E DA TEMPERATURA SOBRE PROPÁGULOS DESSES ENTOMOPATÓGENOS
}

\author{
E.L. Ottati-de-Lima ${ }^{1,2}$, A. Batista Filho ${ }^{1}$, J.E.M. Almeida ${ }^{1}$, \\ M.H. Gassen ${ }^{1}$, I.M. Wenzel ${ }^{1}$, A.M.B. de Almeida ${ }^{1}$, L.O. Zapellini ${ }^{1}$ \\ ${ }^{1}$ Instituto Biológico, Centro Experimental Central, Rod. Heitor Penteado, km 3, CEP 13092-543, Campinas, \\ SP, Brasil. E-mail: batistaf@biologico.sp.gov.br
}

\section{RESUMO}

O trabalho teve os seguintes objetivos: 1) avaliar diferentes substratos para a produção semissólida dos fungos Metarhizium anisopliae e Beauveria bassiana; 2) verificar a tolerância dos conídios produzidos ao efeito da radiação ultravioleta e da temperatura; e 3) avaliar a patogenicidade dos conídios a Diatraea saccharalis. Para ambos os fungos, foram utilizadas 6 repetições para cada tratamento: amido de milho, arroz integral, arroz parboilizado tipo1, arroz tipo 1 e 2, aveia em flocos, canjiquinha, farelo de trigo, farinhas de mandioca crua, de milho amarela e de trigo especial, fubá, milho em grãos, polvilho azedo, soja em grãos, trigo moído e turfa. Os conídios foram quantificados em câmara de Neubauer e a determinação da viabilidade foi realizada através da observação em microscópio, dos conídios germinados e não germinados, após espalhamento da suspensão fúngica em placas de Petri contendo BDA. No ensaio com radiação os fungos foram expostos à radiação por 25 e 50 segundos e foi considerado um tratamento sem exposição; para temperatura os fungos foram expostos a 20, 25, 30 e $35^{\circ} \mathrm{C}$. Utilizando a torre de Potter, $2 \mathrm{~mL}$ de cada suspensão fúngica dos tratamentos foram pulverizados em lagartas de D. saccharalis. As maiores concentrações de conídios de M. anisopliae e B. bassiana foram encontradas nos tratamentos com arroz parboilizado tipo 1, arroz tipo 1 e 2, farinha de milho amarela, fubá e trigo moído e a viabilidade dos conídios produzidos superou os 94\%. Quanto maior o tempo de exposição à radiação menor foi o número de conídios viáveis; também ocorreu perda significativa da viabilidade dos conídios quando expostos à temperatura de $35^{\circ} \mathrm{C}$. Os fungos foram patogênicos para D. saccharalis.

PALAVRAS-CHAVE: Controle microbiano, fungos entomopatogênicos, bioinseticidas, Insecta, meios de cultura.

\begin{abstract}
SEMI-SOLID PRODUCTION OF METARHIZIUM ANISOPLIAE (METSCH.) SOROK AND BEAUVERIA BASSIANA (BALS.) VUILL ON DIFFERENT MEDIA AND THE EFFECTS OF ULTRAVIOLET RADIATION AND TEMPERATURE ON THE INFECTIVE PROPAGULES OF THESE FUNGI. The present study was aimed to evaluate different (semi-solid) media for the production of Metarhizium anisopliae and Beauveriabassiana propagules, and to evaluate the tolerance of these propagules to ultraviolet radiation and temperature. The experiments were performed at the Biological Control Laboratory of the Instituto Biológico at Campinas, São Paulo, Brazil. For both fungi, 6 repetitions were performed for each of the 17 treatments: corn starch, full rice, parboiled rice, type-1 rice, type- 2 rice, oat flakes, canjiquinha [grits], wheat flour, raw cassava flour, yellow corn flour, special wheat flour, corn flour, corn in grains, cassava starch, soy in grains, crushed wheat, and turf. The viability analysis was done in plastic plates containing BDA. For the bioassays involving exposure to ultraviolet light and temperature, BDA was also used for viability analysis, and each treatment was exposed to the UV radiation for 0,25 and 50 seconds, the temperature exposure being at 20,25, 30 and $35^{\circ} \mathrm{C}$. Using a Potter tower, $2 \mathrm{~mL}$ of fungus suspension from each treatment was inoculated to the Diatraea saccharalis caterpillars. Regarding the sporulation, the largest concentrations of M. anisopliae and B. bassiana were found for the treatments with parboiled rice, type- 1 rice, type- 2 rice, yellow corn flour, corn flour and crushed wheat. The viability of all treatments was superior to $94.00 \%$. Also, the longer the duration of the exposition to the UV, the
\end{abstract}

${ }^{2}$ Universidade Estadual Paulista, Faculdade de Ciências Agronômicas, Botucatu, SP, Brasil. 
smaller the number of fertile conidia. At 350 C, a significant loss of conidia viability was observed, and all the treatments presented some level of virulence.

KEY WORDS: Microbial control, entomopathogenic fungi, bioinsecticide, Insecta, culture media.

\section{INTRODUÇÃO}

Apesar dos fungos Metarhizium anisopliae e Beauveria bassiana serem conhecidos devido à patogenicidade que apresentam para um grande número de insetos, nas condições naturais, muitos problemas ocorrem quando a produção dos fungos é realizada em escala industrial e a sua aplicação é efetuada em grandes áreas. Assim, alguns problemas necessitam ser estudados como: caracterização, padronização de linhagens, métodos de produção massal de conídios, formulações, manutenção de linhagens agressivas, métodos deaplicação, compatibilidade do fungo com inseticidas, controle associado e, principalmente, os fatores que regulam epizootias nas condições de campo (Alves, 1998).

Os entomopatógenos são muito sensíveis aos fatores bióticos e abióticos, que influenciam na sobrevivência, propagação ena infecção do hospedeiro (Goetel et al., 2000). Entre os abióticos, a radiação solar ultravioleta (UV) é a mais importante (FARGUES et al., 1996), pois pode inativar os conídios, provocar danos letais ao DNA e mutações (Nicholson et al., 2000). A viabilidadee atividade biológica dos fungos entomopatogênicos sãoaltamenteinfluenciadas pela temperatura, umidade, substrato, radiação ultravioleta e outros fatores (BATISTA FILHO; CARDELLI, 1986).

Os objetivos deste trabalho foram avaliar diferentes substratos na produção semissólida dos fungos M. anisopliae e B. bassiana, bem como o efeito dos meios na suscetibilidade dos conídios à radiação ultravioleta e diferentes temperaturas e também na patogenicidade dos fungos às lagartas da broca da cana-de-açúcar, Diatraea saccharalis (Fabricius, 1794) (Lepidoptera: Pyrallidae).

\section{MATERIAL E MÉTODOS}

Os experimentos foram conduzidos no Laboratório de Controle Biológico do Instituto Biológico, localizado em Campinas, SP. Os isolados IBCB 425 de M. anisopliae eIBCB 66 de B. bassiana estão depositados na Coleção deMicro-organismos Entomopatogênicos "Oldemar Cardim de Abreu" do mesmo laboratório, onde os conídios puros se encontram armazenados dentro de "eppendorfs" em freezer a $-12^{\circ} \mathrm{C}$.

Isolados utilizados: Para a realização dos ensaios, os isolados foram repicados por meio de 3 pontos equidistantes em placas de Petri contendo meio de cultura BDA (batata-dextrose-ágar) e foram incubados em câmara para germinação (BOD), durante 10 dias na temperatura de $25 \pm 1^{\circ} \mathrm{C}$, UR $70 \pm 1 \%$ e fotofase de 12 horas.

Produção dos fungos, efeito da radiação UV e temperatura: Foram preparados 17 tratamentos: amido de milho, arroz integral tipo 1, arroz parboilizado tipo 1, arroz tipo 1 (testemunha), arroz tipo 2, aveia em flocos, canjiquinha, farelo de trigo, farinha de mandioca crua, farinha de milho amarela, farinha de trigo especial, fubá, milho em grãos, polvilho azedo, soja em grãos, trigo moído e turfa.

Tabela 1 - Quantidades de substrato e água destilada utilizada para o preparo dos meios naturais semissólidos.

\begin{tabular}{lccc}
\hline Substrato & Marca comercial & Quantidade de substrato $(\mathrm{g})$ & Quantidade de água $(\mathrm{mL})$ \\
\hline Amido de milho & Cortesia & 60 & 36 \\
Arroz integral tipo 1 & Ráris & 70 & 30 \\
Arroz parboilizado tipo 1 & Coradini & 60 & 32 \\
Arroz tipo 1 & Namorado & 60 & 32 \\
Arroz tipo 2 & Coradini & 60 & 32 \\
Aveia em flocos & Mais Vita & 60 & 40 \\
Canjiquinha & Cortesia & 60 & 20 \\
Farelo de trigo & Natu's & 40 & 60 \\
Farinha de mandioca crua & Cortesia & 60 & 40 \\
Farinha de milho amarela & Yoki & 60 & 30 \\
Farinha de trigo especial & Dona Benta & 73 & 40 \\
Fubá & Yoki & 60 & 45 \\
Milho em grãos & à granel & 70 & 20 \\
Polvilho azedo & Yoki & 75 & 50 \\
Soja em grãos & Natural Life & 70 & 20 \\
Trigo moído & Hikari & 60 & 35 \\
Turfa & Technes Agrícola & 60 & 10 \\
\hline
\end{tabular}


Os dados contidos na Tabela 1 foram baseados no trabalho de WENZEL et al. (2006) e correspondem às quantidades distribuídas em cada repetição.

Cada substrato foi distribuído em sacos de polipropileno e autoclavado a $1 \mathrm{~atm}$ e $120^{\circ} \mathrm{C}$, durante 30 minutos. Em câmara de fluxo laminar vertical foram inoculados $5 \mathrm{~mL}$ das suspensão fúngica na concentração de $1 \times 10^{8}$ conídios $/ \mathrm{mL}$. Os sacos foram mantidos sobre prateleiras em sala climatizada a $25 \pm$ $1^{\circ} \mathrm{C}$, UR de $70 \pm 10 \%$ e fotofase de $12 \mathrm{~h}$ durante 9 dias.

Os testes foram divididos em três experimentos, devido ao grande número de substratos. Os tratamentos foram compostos por seis repetições e cada uma delas corresponde a um saco. Após a análise estatística, foram selecionados os melhores substratos de cada um dos experimentos.

Para a determinação da concentração dos conídios, foi retirada, ao acaso, uma amostra de $1 \mathrm{~g}$ do substrato com fungo de cada saco plástico, que foi adicionado em $10 \mathrm{~mL}$ de água destilada esterilizada em tubo de ensaio. Após a agitação do tubo de ensaio, foram realizadas diluições em série $\left(10^{-2}\right)$ para a contagem dos conídios em câmara de Neubauer sob microscópio óptico. Após a quantificação dos conídios, foram feitos os testes de viabilidade em placas de Petri de plástico com $9 \mathrm{~cm}$ de diâmetro, contendo BDA, utilizando $0,1 \mathrm{~mL}$ da suspensão de cada tratamento/placa. As placas foram submetidas à lâmpada germicida (radiação UV de 253,7 nm), distantes $25,0 \mathrm{~cm}$ da fonte de radiação, expostas à radiação por 25 e 50 segundos e incubadas por 15 horas em B.O.D. a $25^{\circ}$ C. Um tratamento sem exposição à radiação também foi feito. Foram quantificados os números de conídios germinados e não germinados em microscópio ótico com objetiva de 400x, estabelecendo-se uma proporção de viabilidade.

Para os ensaios de temperatura utilizou-se a mesma metodologia utilizada na radiação ultravioleta, mas sendo que cada tratamento foi exposto a diferentes temperaturas: 20, 25, 30 e $35^{\circ} \mathrm{C}$.

Ensaios de virulência: Para os experimentos de virulência foram realizadas oito repetições, contendo dez lagartas 3 o ínstar de $D$. saccharalis para cada um dos tratamentos selecionados. Cada lote de lagartas foi pulverizado com $2 \mathrm{~mL}$ da suspensão de fungo, na concentração de $1,0 \times 10^{7}$ conídios $/ \mathrm{mL}$, em torre de Potter. As testemunhas foram pulverizadas com água destilada estéril. Em seguida, as lagartas foram transferidas para potes de plástico transparente com tampa de rosca. As lagartas foram alimentadas com colmos de cana-de-açúcar de 3,0 cm de altura. Cada inseto morto foi lavado em álcool 70\% e água destilada esterilizada e transferido para placa de Petri contendo algodão umedecido para confirmação da mortalidade pelo entomopatógeno. As placas foram mantidas em câmara climatizada à temperatura de $25 \pm 1{ }^{\circ} \mathrm{C}$, com fotofase de $12 \mathrm{~h}$ e UR de $70 \pm 10 \%$. Foi avaliada diariamente a mortalidade das brocas por um período de dez dias.

Foi utilizado o delineamento experimental inteiramente casualizado e os dados obtidos foram submetidos à análise de variância, pelo Teste $\mathrm{F}$, a $1 \%$ de probabilidade e as médias, comparadas pelo teste de Tukey, a $5 \%$ de probabilidade. Foi utilizado o programa ESTAT - 2.0 Sistemas de Análises Estatísticas-desenvolvidonaFCAV/ UNESPCampus de Jaboticabal, SP.

\section{RESULTADOS E DISCUSSÃO}

Os resultados das concentrações obtidas nos 17 tratamentos avaliados estão apresentados na Tabela 2. Por meio destes, foram selecionados os substratos que apresentaram as maiores concentrações de conídios para M. anisopliae e B. bassiana: arroz parboilizado tipo 1, arroz tipo 1 (testemunha), arroz tipo 2, canjiquinha, farinha de milho amarela, fubá e trigo moído (Tabela 3).

Os resultados demonstraramque, para M. anisopliae o meio de arroz pode ser substituído pelo fubá e o trigo moído, pois eles superaram o arroz tipo $1 \mathrm{em}$ $6,80 \%$ e $12,56 \%$, respectivamente, na produção de conídios. Para o fungo B. bassiana os meios avaliados não apresentaram superioridade de um substrato em relação aos demais (Tabela 3).

Aquino (1974) comprovou a superioridade do meio de arroz em relação ao de batata-dextrose e o de amido, na frutificação e desenvolvimento do fungo em menor espaço de tempo. MARQues; VILAS BOAS (1973) verificaram o bom crescimento e esporulação do fungo nesse meio e outros autores, como Moura Costa; Magalhães (1974) e Villacorta (1977), utilizaram esse meio para o cultivo do fungo com sucesso.

WeNZELetal.(2006) verificaramqueparaLecanicillium lecanii o arroz não foi o substrato mais produtivo, sendo que as maiores produções de conídios ocorreram nos substratos com trigo moído, farelo de soja e farelo de trigo, assim como MACHADO et al. (2009) que verificaram que farelo de trigo e lentilha, além de trigo grosso e sorgo, favoreceram a produção de conídios de L. lecanii.

Diante desses resultados verifica-se que substratos à base de trigo também são boas alternativas para a produção, desde que sejam economicamente viáveis.

A viabilidade de M. anisopliae não foi prejudicada pelo cultivo do fungo nos diferentes substratos, pois, apesar da diferença estatística observada em todos os tratamentos, a porcentagem de germinação foi maior que $94 \%$. Para o fungo B. bassiana, não foi verificada diferença estatística e a porcentagem de germinação dos conídios também superou os 94\% (Tabela 4). 
Tabela 2 - Concentração média de conídios de Metarhizium anisopliae (IBCB 425) e Beauveria bassiana (IBCB 66) obtida em substratos semissólidos após 9 dias de cultivo (Temperatura de $25 \pm 1^{\circ} \mathrm{C}$, UR de $70 \pm 10 \%$ e fotofase de $12 \mathrm{~h}$ ).

\begin{tabular}{|c|c|c|c|c|}
\hline \multirow{2}{*}{ Tratamentos (Experimento 1) } & \multicolumn{4}{|c|}{ Concentração ( $\times 10^{8}$ conídios/mL) } \\
\hline & \multicolumn{2}{|c|}{ M. anisopliae } & \multicolumn{2}{|c|}{ B. bassiana } \\
\hline Arroz integral tipo 1 & 1,65 & $\mathrm{~B}$ & 0,80 & B \\
\hline Arroz parboilizado tipo 1 & 2,40 & A & 0,71 & B \\
\hline Arroz tipo 1 (Testemunha) & 2,10 & $\mathrm{AB}$ & 1,38 & A \\
\hline Arroz tipo 2 & 2,71 & A & 1,09 & $\mathrm{AB}$ \\
\hline Canjiquinha & 2,25 & $\mathrm{AB}$ & 1,34 & A \\
\hline Teste F & 7,1 & & 7,8 & \\
\hline $\mathrm{CV}(\%)$ & 16 & & & \\
\hline Erro padrão da média & 0,1 & & 0,0 & 09 \\
\hline \multirow{2}{*}{ Tratamentos (Experimento 2) } & \multicolumn{4}{|c|}{ Concentração ( x $10^{8}$ conídios $/ \mathrm{mL}$ ) } \\
\hline & \multicolumn{2}{|c|}{ M. anisopliae } & \multicolumn{2}{|c|}{ B. bassiana } \\
\hline Arroz tipo 1 (Testemunha) & 1,37 & B & 2,66 & A \\
\hline Aveia em flocos & 1,71 & B & 0,92 & $\mathrm{BC}$ \\
\hline Farelo de trigo & 1,47 & B & 0,35 & $\mathrm{C}$ \\
\hline Farinha de mandioca crua & 0,38 & $\mathrm{C}$ & 0,92 & $\mathrm{BC}$ \\
\hline Farinha de milho amarela & 1,94 & $\mathrm{AB}$ & 0,96 & B \\
\hline Fubá & 2,57 & $\mathrm{~A}$ & 1,18 & B \\
\hline Teste F & 20, & & 32, & \\
\hline $\mathrm{CV}(\%)$ & 25 & & & \\
\hline Erro padrão da média & 0,1 & & 0,1 & \\
\hline \multirow{2}{*}{ Tratamentos (Experimento 3) } & \multicolumn{4}{|c|}{ Concentração ( $\times 10^{8}$ conídios $\left./ \mathrm{mL}\right)$} \\
\hline & \multicolumn{2}{|c|}{ M. anisopliae } & \multicolumn{2}{|c|}{ B. bassiana } \\
\hline Arroz tipo 1 (Testemunha) & 1,40 & B & 2,19 & A \\
\hline Milho em grãos & 0,82 & $\mathrm{C}$ & 1,13 & C \\
\hline Soja em grãos & 0,80 & $\mathrm{C}$ & 1,14 & $\mathrm{C}$ \\
\hline Trigo em grãos & 0,92 & $\mathrm{C}$ & 1,25 & $\mathrm{C}$ \\
\hline Trigo moído & 1,83 & A & 1,60 & B \\
\hline Turfa & 0,79 & $\mathrm{C}$ & 0,80 & $\mathrm{D}$ \\
\hline Teste F & \multicolumn{2}{|c|}{$79,52^{*}$} & \multicolumn{2}{|c|}{$79,83^{*}$} \\
\hline CV $(\%)$ & \multicolumn{2}{|c|}{10,72} & \multicolumn{2}{|c|}{9,80} \\
\hline Erro padrão da média & \multicolumn{2}{|c|}{0,0478} & \multicolumn{2}{|c|}{0,0541} \\
\hline \multicolumn{5}{|c|}{$\begin{array}{l}\text { Médias seguidas de mesmas letras não diferem significativamente pelo teste de Tukey no nível de } 5 \% \text { de probabilidade. Dados } \\
\text { transformados por } \sqrt{x+0.5} \text {. }\end{array}$} \\
\hline
\end{tabular}

Tabela 3 - Concentração média de conídios de Metarhizium anisopliae (IBCB 425) e Beauveria bassiana (IBCB 66) obtida em substratos semissólidos após 9 dias de cultivo (Temperatura de $25 \pm 1^{\circ} \mathrm{C}$, UR de $70 \pm 10 \%$ e fotofase de $12 \mathrm{~h}$ ).

\begin{tabular}{|c|c|c|c|c|}
\hline \multirow{3}{*}{$\begin{array}{l}\text { Tratamentos } \\
\text { Arroz parboilizado tipo } 1\end{array}$} & \multicolumn{4}{|c|}{ Concentração (x $10^{8}$ conídios/mL) } \\
\hline & \multicolumn{2}{|c|}{ M. anisopliae } & \multicolumn{2}{|c|}{ B. bassiana } \\
\hline & 1,94 & $\mathrm{AB}$ & 1,41 & A \\
\hline Arroz tipo 1 (Testemunha) & 1,91 & $\mathrm{AB}$ & 1,16 & $\mathrm{AB}$ \\
\hline Arroz tipo 2 & 1,94 & $\mathrm{AB}$ & 1,16 & $\mathrm{AB}$ \\
\hline Canjiquinha & 1,36 & B & 1,08 & B \\
\hline Farinha de milho amarela & 1,86 & $\mathrm{AB}$ & 1,14 & $\mathrm{AB}$ \\
\hline Fubá & 2,04 & $\mathrm{~A}$ & 1,34 & $\mathrm{AB}$ \\
\hline Trigo moído & 2,15 & A & 1,30 & $\mathrm{AB}$ \\
\hline Teste F & \multicolumn{2}{|c|}{$2,99 *$} & \multicolumn{2}{|c|}{$3,95^{*}$} \\
\hline $\mathrm{CV}(\%)$ & \multicolumn{2}{|c|}{18,89} & \multicolumn{2}{|c|}{12,22} \\
\hline Erro padrão da média & \multicolumn{2}{|c|}{0,1455} & \multicolumn{2}{|c|}{0,0613} \\
\hline
\end{tabular}

Médias seguidas de mesmas letras não diferem significativamente pelo teste de Tukey no nível de 5\% de probabilidade. Dados transformados por $\sqrt{x+0,5}$.

*significativo a $5 \%$ de probabilidade pelo Teste F.

$\mathrm{CV}=$ Coeficiente de variação. 
Tabela 4 - Viabilidade (\%) de Metarhizium anisopliae (IBCB 425) e Beauveria bassiana (IBCB 66) obtida em substratos semissólidos após 15 horas de incubação (Temperatura de $25 \pm 1^{\circ} \mathrm{C}$, UR de $70 \pm 10 \%$ e fotofase de $12 \mathrm{~h}$ ).

\begin{tabular}{|c|c|c|c|c|}
\hline \multirow{3}{*}{$\begin{array}{l}\text { Tratamentos } \\
\text { Arroz parboilizado tipo } 1\end{array}$} & \multicolumn{4}{|c|}{ Viabilidade (\%) } \\
\hline & \multicolumn{2}{|c|}{ M. anisopliae } & \multicolumn{2}{|c|}{ B. bassiana } \\
\hline & 94,67 & $\mathrm{C}$ & 97,08 & A \\
\hline Arroz tipo 1 (Testemunha) & 98,25 & $\mathrm{AB}$ & 95,42 & A \\
\hline Arroz tipo 2 & 97,33 & $\mathrm{AB}$ & 95,25 & A \\
\hline Canjiquinha & 96,00 & $\mathrm{BC}$ & 96,83 & A \\
\hline Farinha de milho amarela & 98,83 & A & 94,58 & A \\
\hline Fubá & 97,50 & $\mathrm{AB}$ & 97,25 & A \\
\hline Trigo moído & 99,08 & $\mathrm{~A}$ & 95,50 & $\mathrm{~A}$ \\
\hline Teste F & \multicolumn{2}{|c|}{$7,52^{*}$} & \multicolumn{2}{|c|}{$2,15^{\mathrm{ns}}$} \\
\hline $\mathrm{CV}(\%)$ & \multicolumn{2}{|c|}{1,45} & \multicolumn{2}{|c|}{1,82} \\
\hline Erro padrão da média & \multicolumn{2}{|c|}{0,5777} & \multicolumn{2}{|c|}{0,7145} \\
\hline
\end{tabular}

Médias seguidas de mesmas letras não diferem significativamente pelo teste de Tukey ao nível de 5\% de probabilidade.

*significativo a $5 \%$ de probabilidade pelo Teste $\mathrm{F}$.

${ }^{n s}$ não significativo a $5 \%$ de probabilidade pelo Teste F.

$\mathrm{CV}=$ Coeficiente de variação.

Analisando-se a viabilidade de M. anisopliae, nos substratos selecionados, observou-se que os maiores valores ocorreram nos substratos arroz tipo 1 (testemunha), arroz tipo 2, farinha de milho amarela, fubá e trigo moído (Tabela 4), concordando com os resultados obtidos nos estudos de VILAs BoAs et al. (1996).

Analisando-se os efeitos da radiação UV sobre os conídios de $M$. anisopliae, observou-se que houve diminuição gradativa da viabilidade à medida que se aumentou o tempo de exposição à radiação (Tabela 5). Em todos os tempos de exposição ao raio UV o único substrato que manteve sua viabilidade superior quando comparado aos outros foi a farinha de milho amarela. A viabilidade em 50 segundos de exposição foi de $23,67 \%$ e a do arroz tipo 1 foi de $4,17 \%$. Apenas 25 segundos de exposição à radiação UV foram suficientes para baixar os índices de germinação dos conídios produzidos em trigo moído de $99,08 \%$ para $16,50 \%$ (Tabela 5 ).

$\mathrm{Na}$ análise feita com B. bassiana, novamente, a farinha de milho amarela se apresentou como um dos melhores substratos, seguido por canjiquinha (Tabela 5). Também a exposição por 25 segundos à radiação UV foi suficiente para baixar o índice de germinação dos conídios produzidos em arroz parboilizado tipo 1 de $97,08 \%$ para $32,67 \%$ (Tabela 5). Também pode ser observado que os conídios de B. bassiana no tempo de exposição de 50 segundos foram mais resistentes dos que os de M. anisopliae.

Segundo Braga et al. (2002), a maioria desses micro-organismos não possui proteção contra os efeitos deletérios da luz solar.

Os efeitos letais causados por luz UV (253 nm) foram demonstrados por CoRrêA (1983), FrIGO
(1983) e outros. Verifica-se que há uma grande variabilidade entre isolados e sugerem que os mais resistentes sejam utilizados em programas de melhoramento.

Analisando-se o efeito das temperaturas sobre os conídios de M. anisopliae produzidos nos substratos selecionados, observou-se que o arroz tipo 1 (testemunha), farinha de milho amarela, fubá e o trigo moído foram os que apresentaram bons resultados em toda a faixa de temperatura avaliada. A maior viabilidade de conídios é observada na temperatura de $25^{\circ} \mathrm{C}$ em todos os tratamentos (Tabela 6). Entre $30^{\circ} \mathrm{C}$ e $35^{\circ} \mathrm{C}$ não houve diferença significativa de viabilidade entre os tratamentos: arroz parboilizado tipo 1, arroz tipo 1 (testemunha), arroz tipo 2, farinha de milho amarela, fubá e trigo moído. Os resultados observados na temperatura de $20^{\circ} \mathrm{C}$ não têm diferença significativa dos resultados observados na temperatura de $30^{\circ} \mathrm{C}$.

VILLACORTA (1978), trabalhando com diferentes isolados de $M$. anisopliae, verificou que a $37^{\circ} \mathrm{C}$ houve inibição da germinação de conídios tornando-os inviáveis quando eles eram submetidos por mais de 96 horas a essa temperatura. A temperatura máxima a que os fungos foram expostos no presente trabalho foi de $35^{\circ} \mathrm{C}$. Nessa temperatura, a viabilidade dos conídios foi significativamente mais baixa do que a obtida a $25^{\circ} \mathrm{C}$, considerada como temperatura ótima, comprovando o declínio de viabilidade a partir dos $30^{\circ} \mathrm{C}$. Mesmo com as viabilidades mais baixas, quando expostas à temperatura de $35^{\circ} \mathrm{C}$, a germinação dos conídios foi superior a $80 \%$ nos substratos arroz tipo 1, farinha de milho amarela, fubá e trigo moído Tabela 7). 


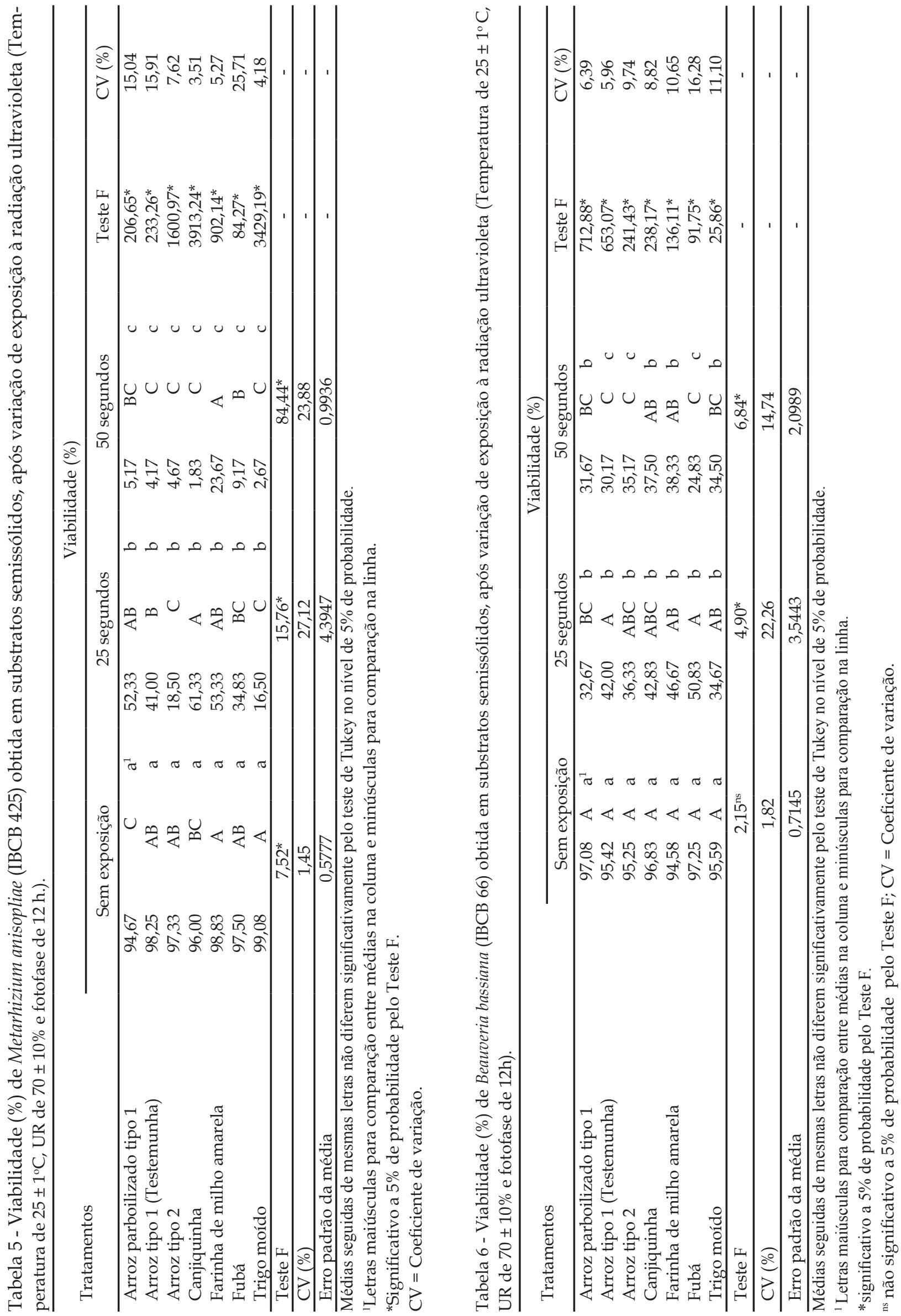



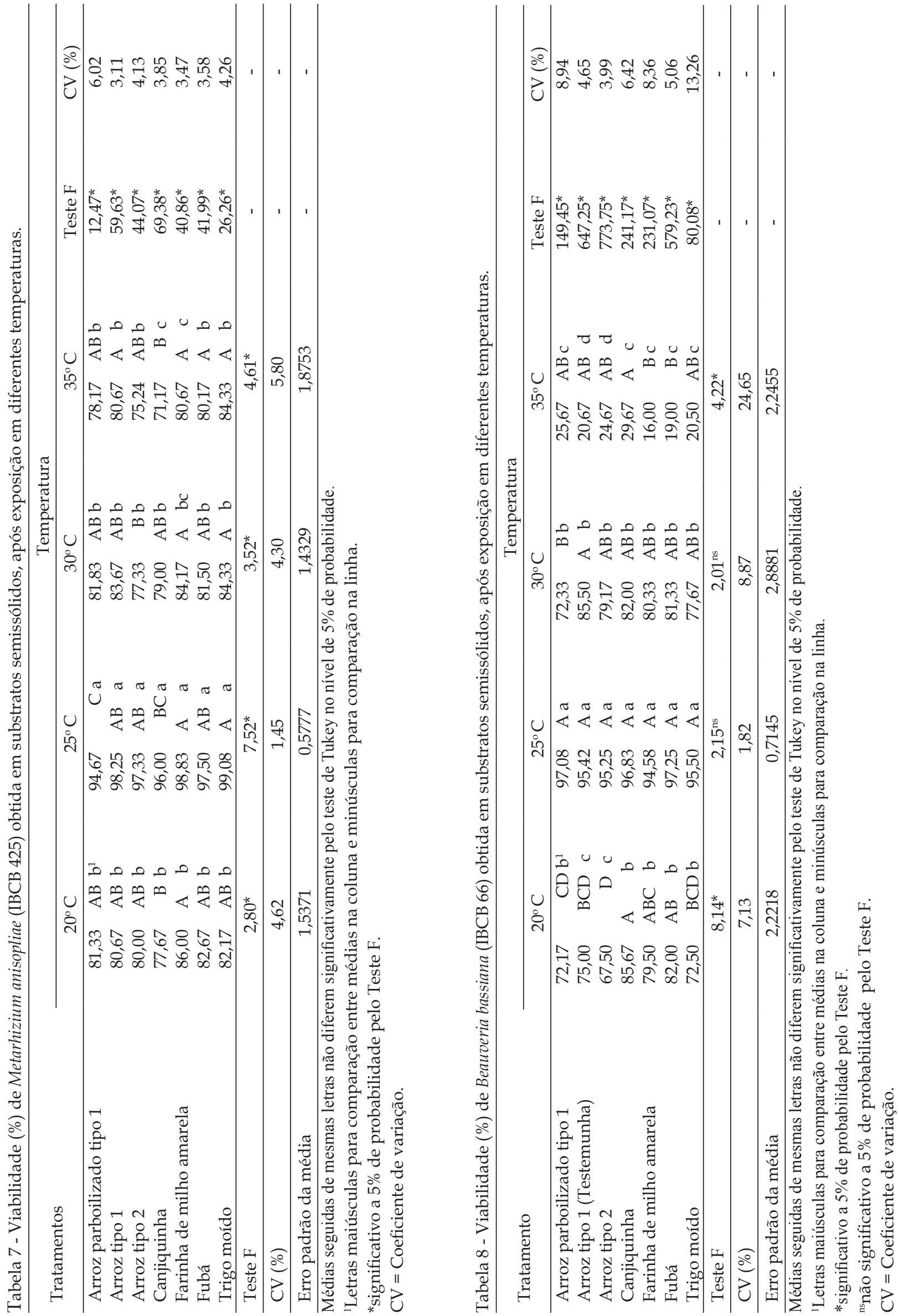
Tabela 9 - Mortalidade confirmada (\%) de lagartas de 3o ínstar de Diatraea saccharalis após aplicação das diferentes suspensões de Metarhizium anisopliae e Beauveria bassiana, obtidas em meios de cultura semissólidos (Temperatura de $25 \pm$ $1^{\circ} \mathrm{C}$, UR de $70 \pm 10 \%$ e fotofase de $12 \mathrm{~h}$ ).

\begin{tabular}{|c|c|c|c|c|}
\hline \multirow{3}{*}{$\begin{array}{l}\text { Tratamentos } \\
\text { Arroz parboilizado tipo } 1\end{array}$} & \multicolumn{4}{|c|}{ Mortalidade Confirmada (\%) } \\
\hline & \multicolumn{2}{|c|}{ M. anisopliae } & \multicolumn{2}{|c|}{ B. bassiana } \\
\hline & 95,00 & A & 98,75 & $\mathrm{~A}$ \\
\hline Arroz tipo 1 (Testemunha) & 91,25 & $\mathrm{AB}$ & 98,75 & $\mathrm{~A}$ \\
\hline Arroz tipo 2 & 85,00 & $\mathrm{AB}$ & 98,75 & A \\
\hline Canjiquinha & 87,50 & $\mathrm{AB}$ & 98,75 & A \\
\hline Farinha de milho amarela & 75,00 & B & 93,75 & $\mathrm{~A}$ \\
\hline Fubá & 90,00 & $\mathrm{AB}$ & 93,75 & $\mathrm{~A}$ \\
\hline Trigo moído & 85,00 & $\mathrm{AB}$ & 100,00 & A \\
\hline Testemunha (água destilada) & 3,75 & $\mathrm{C}$ & 2,50 & B \\
\hline Teste F & \multicolumn{2}{|c|}{$59,10^{*}$} & \multicolumn{2}{|c|}{$118,83^{*}$} \\
\hline $\mathrm{CV}(\%)$ & \multicolumn{2}{|c|}{14,42} & \multicolumn{2}{|c|}{10,20} \\
\hline Erro padrão da média & \multicolumn{2}{|c|}{0,3903} & \multicolumn{2}{|c|}{0,3089} \\
\hline
\end{tabular}

Médias seguidas de mesmas letras não diferem significativamente pelo teste de Tukey no nível de 5\% de probabilidade. *significativo a $5 \%$ de probabilidade pelo Teste F.

$\mathrm{CV}=$ Coeficiente de variação.

A mesma análise executada sobre os dados obtidos com B. bassiana mostrou que as maiores viabilidades ocorreram nos seguintes substratos, de acordo com a temperatura aplicada: $20^{\circ} \mathrm{C}-$ canjiquinha, farinha de milho amarela e fubá; $25^{\circ}$ C - não foi observada diferença significativa entre os tratamentos; $30^{\circ} \mathrm{C}$ - arroz tipo 1 (testemunha), arroz tipo 2, canjiquinha, farinha de milho amarela, fubá e trigo moído; $35^{\circ} \mathrm{C}$ - arroz parboilizado tipo 1 , arroz tipo 1 (testemunha), arroz tipo 2 canjiquinha e trigo moído. Na temperatura de $30^{\circ} \mathrm{C}$, os substratos arroz tipo 1 (testemunha) e arroz tipo 2, apresentaram aumento de viabilidade, comparando-se com a temperatura de $20^{\circ} \mathrm{C}$. Os demais substratos não apresentaram diferença significativa comparando-se à viabilidade obtida com estes, aos $20 \mathrm{e} 30^{\circ} \mathrm{C}$ (Tabela 8). Os conídios de B. bassiana são bastante sensíveis em temperaturas acima de $30^{\circ} \mathrm{C}$ ocorrendo menor viabilidade a partir dessa temperatura. Na temperatura de $35^{\circ} \mathrm{C}$, a porcentagem de germinação variou nos diferentes substratos entre 16 e $29,67 \%$.

Os fungos mitospóricos M. anisopliae, B. bassiana e Nomuraea rileyi apresentam faixas de temperatura favoráveis para o desenvolvimento de 24 a $30^{\circ} \mathrm{C}, 22$ a $26^{\circ} \mathrm{C}$ e 20 a $30^{\circ} \mathrm{C}$, respectivamente (Alves, 1998).

Através da confirmação da mortalidade das lagartas de $D$. saccharalis, observou-se que os conídios do fungo $M$. anisopliae apresentaram maior virulência quando produzidos em arroz parboilizado tipo 1, arroz tipo1 (testemunha), arroz tipo 2, canjiquinha, fubá e trigo moído, sendo que mortalidade confirmada foi igual ou superior a $85 \%$. A menor porcentagem de mortalidade foi observada no tratamento com farinha de milho amarela (75\%) (Tabela 9). No caso de B. bassiana não houve diferença significativa entre os tratamentos, sendo que todos, apresentaram maior virulência do que $M$. anisopliae variando entre $93,75 \%$ (farinha de trigo amarela) e 100\% (trigo moído) de mortalidade confirmada (Tabela 9).

MACEDO et al. (1990) observaram que B. bassiana provocou, com a mesma dosagem, mortalidade entre 38 e $80 \%$ quando inoculado em $D$. saccharalis, enquanto que $M$. anisopliae provocou mortalidade entre 18 e $50 \%$, quando inoculado neste inseto. No presente trabalho, a mortalidade confirmada para B. bassiana variou entre 93 e $100 \%$ e M. anisopliae apresentou mortalidade entre 75 e $95 \%$.

\section{CONCLUSÕES}

Os melhores substratos para a produção de conídios de ambos os fungos, $M$. anisopliae e $B$. bassiana são: arroz parboilizado tipo 1, arroz tipo 1 (testemunha), arroz tipo 2, canjiquinha, farinha de milho amarela, fubá e trigo moído e a viabilidade dos conídios produzidos foi alta.

A radiação UV influencia a viabilidade dos conídios produzidos, sendo $B$. bassiana mais sensível do que $M$. anisopliae;

A temperatura de $35^{\circ} \mathrm{C}$ afeta a viabilidade dos conídios de B. bassiana;

Os conídios dos fungos, M. anisopliae e B. bassiana, produzidos nos diferentes substratos são patogênicos às lagartas $3^{\circ}$ instar de $D$. saccharalis. 


\section{REFERÊNCIAS}

ALVES, S.B. Patologia e controle microbiano.

In: (Ed.). Controle microbiano de insetos. Piracicaba: FEALQ, 1998. p.637-711.

AQUINO, M.L.N. O fungo entomopatogênico Metarhizium anisopliae (Metsch) Sorokin, no Estado de Pernambuco. Boletim Técnico do Instituto de Pesquisas Agronômicas, v.72, p.1-26, 1974.

BATISTA FILHO, A.; CARDELLI, M.A. Viabilidade dos esporos de B. bassiana (Bals.) Vuill. isolados de bicudo do algodoeiro (Anthonomus grandis Boheman) obtidos em diferentes meios de cultura e armazenados a diferentes temperaturas. Biológico, São Paulo, v.52, p.57-59, 1986.

BRAGA, G.U.L.; FLINT, S.D.; RANGEL, D.E.N.; MILLER, C.D.; FREIMOSER, F.; LEGER, R.J.; ANDERSON, A.J.; ROBERTS, D.W. Damage to fungi from solar-UV exposure, and genetic and molecular-biology approaches to mitigation. In: INTERNATIONAL COLLOQUIUM ON INSECT PATHOLOGY AND MICROBIAL CONTROL, 2002, Londrina, PR. Proceedings. Londrina: 2002. p.241-245.

CORRÊA, G.S. Influência da radiação ultravioleta e solar na viabilidade de conídios de Metarhizium anisopliae (Metsch) Sorokin. 1983. 84f. Dissertação (Mestrado) - Escola Superior de Agricultura "Luiz de Queiroz", Universidade de São Paulo, Piracicaba, 1983.

FARGUES, J.; GOETTEL, M.S.; SMITS, N.; OUEDRAOGO, A.; VIDAL, C.; LACEY, L.A.; LOMER, C.J.; ROUGIER, M.. Variability in susceptibility to simulated sunlight of conidia among isolates of entomopathogenic hyphomycetes. Mycopathologia, v.135, p.171-181, 1996.

FRIGO, S.M. Variabilidade e fusão de protoplastos em Metarhizium anisopliae (Metsch.) Sorokin. 1983. 116f. Tese (Doutorado) - Escola Superior de Agricultura "Luiz de Queiroz", Universidade de São Paulo, Piracicaba, 1983.

GOETTEL, M.S.; INGLIS, G.D.; WRAIGHT, S.P. Fungi. In:__ Field manual of techniques in invertebrate pathology. Netherlands: Kluver Academic Publishers, 2000. p.255-282.

MACEDO, N.C.; ALVES, S.B.; SALOMÃO, R.; BOTELHO, P.S.M. Suscetibilidade de Diatraea saccharalis (Fabr., 1794) criadas em diferentes espécies vegetais aos fungos Metarhizium anisopliae (Metsch.) sorok. e Beauveria bassiana (Bals.) Vuill. Ecossistema, v.15, p.19-23, 1990.
MACHADO, A.C.R.; MONTEIRO, A.C.; MOCHI, D.A.; YOSHIDA, L. Resíduos e subprodutos agroindustriais e grãos como substratos para a produção do fungo entomopatogênico Lecanicillium lecanii. Bragantia, v.68, n.3, p.703-714, 2009.

MARQUES, E.J.; VILLAS BOAS, A.M. Contribuição ao estudo da cultura e aplicação de Metarhizium anisopliae (Metsch) no controle da cigarrinha da folha (Mahanarva posticata Stal) no Nordeste do Brasil. In: REUNIÃO ANUAL DA SOCIEDADE ENTOMOLÓGICA DO BRASIL, 1., 1973, Viçosa, MG. Livro de Resumos. Viçosa: 1973. p.70.

MOURA-COSTA, M.D.; MAGALHÃES, C.D. Um novo meio de cultura para o fungo entomógeno Metarhizium anisopliae (Metsch) Sorokin, parasito da "cigarrinha" das pastagens. Boletim do Instituto Biológico da Bahia, v.13, p.57-60, 1974.

NICHOLSON, W.L.; MUNAKATA, N.; HORNECK, G.; MELOSH, H.J.; SETLOW, P. Resistence of Bacillus endospores to extreme terrestrial and extraterrestrial environments. Microbiology and Molecular Biology Reviews, v.64, n.3, p.548-572, 2000.

VILAS BOAS, A.M.; ANDRADE, R.M.; OLIVEIRA, J.V. Diversificação de meios de cultura para a produção de fungos entomopatogênicos. Arquivos de Biologia e Tecnologia, v.39, n.1, p.123-128, 1996.

VILLACORTA, A. Technique for the mass culture of the entomophagous fungus Metarhizium anisopliae (Metsch.) Sorokin in granular form. Anais da Sociedade Entomológica do Brasil, v.5, p.101-104, 1977.

VILLACORTA, A. Efeito da temperatura e nutrição sobre o desenvolvimento de vários isolados de Metarhizium anisopliae Sorokin. In: CONGRESSO LATINO AMERICANO DE ENTOMOLOGIA, 3.; CONGRESSO BRASILEIRO DE ENTOMOLOGIA, 5., 1978, Bahia, Livro de Resumos. Bahia: 1978. p.70.

WENZEL, I.M.; MONTEIRO, A.C.; PEREIRA, G.T. Produção de conídios de Lecanicillium lecanii substratos sólidos obtidos de grãos. Científica, v.34, n.1, p.7-14, 2006.

Recebido em 05/3/07

Aceito em 31/8/10 